\title{
Bhore Committee (1946) and its Relevance Today
}

\author{
Ravi Duggal \\ Foundation for Research in Community Health, Bombay
}

The Health Survey and Development Committee, popularly known as the Bhore Committee, is now 45 years old. Its relevance is not lost even today. This paper briefly reviews the entire three volume report to highlight its wide scope and its comprehensive and progressive nature. It was in the midst of the Second World War and in succession to the Quit-India movement that the Government of India on 18th October 1943 announced the appointment of the Health Survey and Development Committee under the Chairmanship of Sir Joseph Bhore. The terms of reference were simple: (a) a broad survey of the present position in regard to health conditions and health organization in British India, and $(b)$ recommendation for future development. To lend support to the Committee, five Advisory Committees were formed : (i) Public Health (ii) Medical Relief (iii) Professional Education (iv) Medical Research and (v) Industrial Health. The advisory Committee deliberations, tours (in all provinces except Assam and Baluchistan), interviews, observations etc. resulted in 206 background papers, memoranda and notes which formed the basis of the final report. This task was accomplished in 26 months.

Reprint requests : Dr. Ravi Duggal, Scnior Research Officer, The Foundation for Research in Community Health, 84-A, R.G. Thadani Marg, Worli, Bombay-400018.
The Bhore Committee begins with a comparison of the Indian health situation with other countries. (Sce Table 1)

The poor state of India's health (IMR and life expectancy) in comparison to other countries, especially the developed ones is apparent. But what is more tragic is that today, 53 years later, India has not reached the level of health which-developed countries had achieved before the start of World War!

At the time of the Bhore Committee the health of children and women was still worse. Of all deaths in India in the pre-war years $48 \%$ were that of children below 10 years, in comparison to only $10 \%$ in England and Wales, and maternal mortality was 20 per 1000 confinements in India in contrast to about 3 per 1000 in England. The comparison is even worse today as in India still over $40 \%$ of the deaths continue to be in the under-10 years age group and maternal mortality is higher than 5 per 1000 .

The causes of this low level of health in India were the same causes which are responsible for poor health of Indians even today : $(i)$ insanitary conditions : the development of public health was very poor inspite of reforms that began since 1860 . As stated earlier these reforms were only in enclaves where the military or civil 
TABle 1. Comparison of Mortality and Life Expectancy

\begin{tabular}{|c|c|c|c|c|c|c|c|c|}
\hline \multirow[b]{3}{*}{ Country } & \multirow{3}{*}{$\frac{\text { Death Rat }}{(1937)}$} & \multirow{3}{*}{$\frac{\text { IMR }}{(1937)}$} & \multirow{2}{*}{\multicolumn{2}{|c|}{ Life Expectancy at Birth }} & \multicolumn{4}{|c|}{1987} \\
\hline & & & & & Death & Life & Expect & ancy \\
\hline & & & Males & Females & $\begin{array}{l}\text { Death } \\
\text { Rate }\end{array}$ & IMR & Male & Female \\
\hline New Zealand & 9.1 & 31 & 65.04 & $67.88(1931)$ & 9 & 11 & 72 & 78 \\
\hline Australia & 9.4 & 38 & 63.48 & $67.14(1932-34)$ & 8 & 10 & 73 & 80 \\
\hline $\begin{array}{l}\text { Union of } \\
\text { S. Africa }\end{array}$ & 10.1 & 37 & 57.78 & $\begin{array}{l}61.48 \text { (1925-27) } \\
\text { (Europeans } \\
\text { only) }\end{array}$ & ${ }^{10}(\mathrm{Bl}$ & $\begin{array}{l}72 \\
\text { cks \& }\end{array}$ & $\begin{array}{c}58 \\
\text { White) }\end{array}$ & 64 \\
\hline Canada & 10.2 & 76 & 59.32 & $61.59(1929-31)$ & 8 & 8 & 73 & 80 \\
\hline U.S.A. & 11.2 & 54 & $\begin{array}{l}59.12 \\
47.55\end{array}$ & $\begin{array}{l}62.67 \text { (Whites) } \\
49.51 \text { (Blacks) }\end{array}$ & 9 & $\begin{array}{l}10 \\
\text { cks \& }\end{array}$ & $\begin{array}{c}72 \\
\text { White) }\end{array}$ & 74 \\
\hline Germany & 11.7 & 64 & 59.86 & $62.75(1932-43)$ & ${ }^{12}(\mathrm{~W}$ & $\begin{array}{c}8 \\
\text { Germ }\end{array}$ & $\begin{array}{l}72 \\
\text { any) }\end{array}$ & 78 \\
\hline $\begin{array}{l}\text { England \& } \\
\text { Wales }\end{array}$ & 12.4 & 58 & 58.74 & $62.88(1930-32)$ & 12 & 9 & 72 & 78 \\
\hline Italy & 14.2 & 109 & 53.76 & $56.00(1930-32)$ & 10 & 10 & 74 & 80 \\
\hline France & 15.0 & 65 & 54.30 & $59.02(1928-33)$ & 10 & 8 & 74 & 80 \\
\hline Japan & 17.0 & 106 & 44.82 & $46.54(1926-30)$ & 7 & 6 & 75 & 81 \\
\hline Java & 18.8 & - & - & - & 9 & $\begin{array}{l}71 \\
\text { lonesia }\end{array}$ & 58 & 62 \\
\hline Palestine & 18.9 & 153 & - & - & - & - & - & - \\
\hline Ceylon & 21.7 & 158 & - & - & 6 & 33 & 68 & 73 \\
\hline British India & 22.4 & 162 & 26.91 & $26.56(1921-30)$ & 11 & 99 & 58 & 58 \\
\hline Egypt & 27.2 & 165 & - & - & 10 & 85 & 59 & 62 \\
\hline
\end{tabular}

(*Source for 1987 data : World Development Report, World Bank)

administration resided. The concern for the "native" population was there only as far as it affected those staying in enclaves, for example, when there was an epidemic outbreak.

(ii) Defective nutrition : Malnutrition and undernutrition reduce the vitality and power of resistance of an appreciable section of the population. About 80 to 90 per cent of the food consumed by Indians consists of cereals and in the 1939-43 period cven this fell short (in terms of availability) by 22 per cent.

(iii) Inadequacy of the existing medical and preventive health organisation : The existing facilities are only a fraction of the requirement on the basis of any decent standards. A comparison of India and United Kingdom for the year 1942-43 shows the 
following ratios (Table 2).

(iv) Lack of general and health education : It must be clarified that the Bhore Committee did not view these causes as independent of each other. They werc scen as being interrelated, and overriding these causes were unemployment and poverty which were considered by the Committee to constitute the social background of illhealth.

\section{THE POLITICAL ECONOMY OF A NATIONAL HEALTH PLAN}

The Bhore Committce continues in Volume II. "It is not for us to apportion responsibility for the sombre realities which face us today. It is with the future that we are concerned and.if the picture is to be substantially altered for the better with the least possible delay, a nation-wide interest must be aroused and the irresistible forces of an awakened public opinion essayed in the war against disease. Only a vivid realization of the grievous handicap which is today retard- ing the country's progress can help to mobilize an all-out effort in this campaign and infuse into it a driving force which will gather and not lose momentum as time goes on. If it were possible to evaluate the loss which this country annually suffers through the avoidable waste of valuable human material and the lowering of human efficiency through malnutrition and preventable morbidity, we feel that the result would be so startling that the whole country would be aroused and would not rest until a radical change had been brought about."

In designing this plan the Committee clcarly indicated that the national health services would be an integral part of an overall programme of reconstruction. "We should be failing in our duty if we omitted to stress the composite character of the problem with which we are faced and to point out that a frontal attack upon one sector alone can only end in disappointment and a waste of money and effort."

The Bhore Committee concluded that

TABLE 2. Health Facilities in India and UK in 1942-43 and in India in 1987.

\begin{tabular}{|c|c|c|c|c|c|c|}
\hline \multirow[b]{2}{*}{ Categories } & \multicolumn{5}{|c|}{ Population per facility } & \multirow{2}{*}{$\begin{array}{l}\text { India } \\
1987^{*}\end{array}$} \\
\hline & & $\begin{array}{l}\text { India } \\
\qquad 1942-6\end{array}$ & U.K. & & & \\
\hline $\begin{array}{l}\text { Doctors } \\
\text { (Allopathic) }\end{array}$ & 1 to & 6,300 & 1 to & 1,000 & 1 to 2,330 & $\begin{array}{l}\text { (1 to } 1000 \text { including } \\
\text { non-allopathic doctors }\end{array}$ \\
\hline Nurses & 1 to & 43,000 & 110 & 300 & 1 to 3,480 & \\
\hline $\begin{array}{l}\text { Health } \\
\text { Visitors }\end{array}$ & 1 to & 400,000 & 1 to & 4,770 & 1 to 60,000 & \\
\hline Midwives & 1 to & 60,000 & 1 to & 618 & 1 to 4,300 & $\begin{array}{l}1 \text { to } 2133 \text { including } \\
\text { ANMS) }\end{array}$ \\
\hline Dentists & 1 to & 300,000 & 1 to & 2,700 & 1 to 80,000 & $\cdot$ \\
\hline Hospital Beds & 1 to & 4,167 & 1 to & 140 & 1 to 1,310 & \\
\hline
\end{tabular}

* Source for 1987 data : Health Information of India, 1987, CBHI, Government of India, 1988. 
health care services would be available to all citizens, irrespective of their ability to pay, and that it should be a complete medical service, domiciliary and institutional, in which all the facilities required for the treatment and prevention of disease as well as for the promotion of positive health are provided. "Thus there should be provision for every patient, if his condition requires it, to secure the consultant, laboratory and other special services which may be necessary for diagnosis and treatment. There should also be provision for the periodical medical examination of every person, sick or healthy, so as to ensure that his physical condition is appraised from time to time and that suitable advice and medical aid, whereever necessary, are given in order to enable him to maintain his health at the highest possible level."

The Bhore Committee felt that a very large section of the. people are living below the normal subsistence level and cannot afford as yet even the small contribution that an insurance scheme will require. "We therefore consider that medical benefits will have, in any case, to be supplied free to this section of the population until atleast its economic condition is materially improved. We are averse to drawing any line of distinction between sections of the community which are and are not in a position to pay for such benefits. The absence of certain amenities and services in the countryside has proved deterrent to medical practitioners leaving the attraction of cities and towns and migrating to the villages. We have, therefore, come to the conclusion that the most satisfactory method of solving this problem would be to provide a whole-time salaried service which will enable governments to ensure that doctors will be made available where their services are nceded.
The evidence tendered by a number of representatives of medical associations, by private individuals and by several responsible medical administrators lends strong support to this proposal.

Further, if the poor in the rural areas must receive equal attention and if preventive work must get done then private practice by whole-time salaried doctors should be prohibited. Theoretically the patient will be free to take treatment in any state institution. But in practice for his own convenience he would go the nearest available. His choice would widen with the expansion of health care facilities.

\section{THE NATIONAL HEALTH PLAN}

Keeping in view the socio-economic and health conditions in India the Bhore Committee set itself the following objectives to be achieved through the plan they were formulating.

1. The services should make adequate provision for the medical care of the individual in the curative and preventive fields and for the active promotion of positive health;

2. These services should be placed as close to the people as possible, in order to ensure their maximum use by the community which they are meant to serve;

3. The health organization should provide for the widest possible basis of co-operation between the health personnel and the people;

4. In order to promote the development of the health program on sound lines the support of the medical and auxiliary professions, such as those of dentists, pharmacists and nurses, is essential; provisions should, therefore, be made for enabling the representatives of these professions to influence the health policy of the country; 
5. In view of the complexity of modern medical practice, from the stand-point of diagnosis and treatment, consultant, laboratory and institutional facilities of a varied character, which together constitute "group", practice should be made available;

6. Special provision will be required for certain sections of the population, e.g., mothers, children, the mentally deficient and others;

7. No individual should fail to secure adequate medical care, curative and preventive, because of inability to pay for it; and

8. The creation and maintenance of as healthy an environment as possible in the homes of the people as well as in the places where they congregate for work, amusement or recreation, are essential.

The Bhore Committee further recognized the vast rural-urban disparitics in the existing health services and hence based its plan with specifically the rural population in mind. It's plan was for the district as a unit.

The district health scheme, also called the three million plan, which represented an average districts population; was to be organized in a 3-tier system. "At the periphery will be the primary unit, the smallest of these three types. A certain number of these primary units will be brought under a secondary unit, which will perform the dual function of providing a more efficient type of health service at its headquarters and of supervising the work of these primary units. The headquarters of the district will be provided with an organization which will include, within its scope, all the facilities that are necessary for modern medical practice as well as the supervisory staff who will be responsible for the health administration of the district in its various specialized types of service."
This health organization would provide integrated health services, curative, preventive and promotive-to the entire population.

In this paper we will discuss only the long term programme which was to be realized within a period of 30 to $\mathbf{4 0}$ years. That is by the early eighties all the facets of the Bhore Committee should have been realized. We are now in the year 1990 and very well know (and it is very humiliating to know) that we are nowhere close to what the Bhore Committee had recommended in 1946 as the minimum requirements for a decent health care delivery system. This embarrassment is only enhanced when we discover that these recommendations of the Bhore Committee were far lower than the level most developed countries had reached on the eve of the World War II!

The level of health care envisaged by the Bhore Committee stated in terms of ratio to a standard unit of population was 567 hospital beds, 62.3 doctors, 150.8 nurses per 100,000 population. As a contrast to this in 1942 in the United Kingdom these ratios were : 714 beds, 100 doctors, 333 nurses per 100,000 population.

And in India of 1988 these ratios lagged at : 76.3 beds, 42.9 doctors per 100,000 population (100 per 100,000 if we include non-allopaths), 28.7 nurses per 100,000 population. The three tier plan of health organisations was as follows :

\section{Primary Unit}

Every 10,000 to 20,000 population (depending on density from one area to another) would have a 75 -bedded hospital served by six medical officers including medical, surgical and obstetrical and gynaecological specialists. This medical staff would be supported by 6 public health nurses, 2 sanitary 
inspectors, 2 health assistants and 6 midwives to provide domiciliary treatment. At the hospital there would be a complement of 20 nurses, 3 hospital social workers, 8 ward attendants, 3 compounders and other non-medical workers.

Two medical officers along with the public health nurses would engage in providing preventive health services and curative treatment at homes of patients. The sanitary inspectors and health assistants would aid the medical team in preventive and promotive work. Preferably at least three of the six doctors should be women.

Of the 75 beds, 25 would cater to medical problems, ten for surgical, ten for obstetrical and gynaecological, twenty for infectious diseases, six for malaria and four for tuberculosis. This primary unit would have adequate ambulatory support to link it to the secondary unit when the need arises for secondary level care. Each province was given the autonomy to organize its primary units in the way it deemed most suitable for its population, but there was to be no compromise on quality and accessibility.

\section{Secondary Unit}

About 30 primary units or less would be under a secondary unit. The secondary unit would be a 650-bedded hospital having all the major specialities with a staff of 140 doctors, 180 nurses and 178 other staff including 15 hospital social workers, 50 ward attendants and 25 compounders. The secondary unit besides being a first level referral hospital would supervise, both the preventive and curative work of the primary units.

The 650 beds of the secondary unit hospital would be distributed as follows : Medical 150, Surgical 200, Obs. \& Gynae 100, Infectious Disease 20, Malaria 10, Tuberculosis 120 , Pediatrics 50. Total 650 .

\section{District Hospital}

Every district centre would have a 2500 beds hospital providing largely tertiary care with 269 doctors, 625 nurses, 50 hospital social workers and 723 other workers. The hospital would have 300 medical beds, 350 surgical beds, 300 obs. \& gynac beds, 540 tuberculosis beds, 250 pediatric beds, 300 leprosy beds, 40 infectious diseases beds, 20 malaria beds and 400 beds for mental diseases. A large number of these district hospitals would have medical colleges attached to them. However, each of the three levels would have functions related to medical education and training, including internship and refresher courses.

\section{Special Services}

In addition to this basic infrastructure the Committee recommended a wide range of other health programs that would provide support and strength to this health organisation.

Certain diseases were singled out for special inputs that would be required to control and/or eradicate them. These diseases were malaria, tuberculosis, small pox, cholera, plague, leprosy, veneral diseases, hook-worm disease, filariasis, guineaworm disease, cancer, mental diseases, mental deficiency and diseases of the eye and blindness.

For all these diseases the Committee found that facilities are grossly inadequate and need urgent attention-"proper sanitation and other public health measures are the key to eradicate or control such diseases."

A review of environmental hygiene by the committee indicated inadequate and poor quality town and village planning, housing, water supply and general 
sanitation. "This is a cause for concern because without this medical relief has little meaning. Hence, a social disease such as tuberculosis can be combated successfully only if ameliorative measures on an extensive scale can be undertaken so as to improve the general standard of living, including housing, nutrition and sanitation of the environment in the home, the workplace and places of public resort."

\section{Health of Mothers and Children}

"Our ultimate aim should be not merely to safeguard maternity but also to provide adequate health protection to all women, in order to ensure that the function of motherhood is undertaken under optimum conditions of health. Special services for the protection of maternity will no doubt be required, but these services should be developed as parts of the wider organization for providing adequate health protection to all women". Keeping this principle in mind special services were recommended by the Committec for the healih of mothers and children within the framework of general health services. The facilitics available at the primary unit would enable the establishment of a maternity and child welfare centre which would have the following functions :

(1) To get in touch with as many pregnant women in the area and to persuade them to visit the clinic regularly. On the first visit a detailed examination of the expectant mothers general and obstetric, should be made and a record of her medical history kept. At subsequent visits advice in respect of the hygiene of pregnancy and instruction regarding diet will be given.

(2) To provide for the skilled assistance of a midwife or trained dai at the time of delivery and for domiciliary visits by a public health nurse for two wceks thereafter.

(3) To keep the mother and child under observation, if possible, for a year. It is desirable to keep a weckly weight record of the infant. Advice to the mother should be given in respect of lactation, diet and exercise and, at a later stage, in respect of weaning. Treatment, where necessary should be given and extra nourishment to mother and child should be made available, if required.

(4) To teach mothercraft in all its branches with practical demonstrations, special emphasis being laid on the inculcation of sound hygienic habits in the mother and child.

(5) To keep children under observation, if possible, upto five years, weight and progress records should be kept. From the second year onwards monthly visits would suffice, but the mother should be instructed to report any illness arising between visits to the clinic and a domiciliary visit by a doctor should, in such cases, be arranged.

(6) To organize occasional talks, by suitable persons, for husbands and fathers in order to secure their cooperation.

(a) in the care of their women, especially during pregnancy,

(b) in the advisability of spacing the births of their children.

(c) in child-psychology,

(d) in aiding their wives in the maintenance of hygicnic surroundings and in providing a well balanced diet for the family; and

(c) in the development of the faculties of children by means of manual occupations, special toys, games etc. ... and

(7) to give instruction on birth control.

Besides the above the Committee recommended provision for a playground for children at the centre with adequate 
facilitics that would make it a social activity area for mothers and children through which health and social education can be imparted by trained social workers.

The Committee also recommended the establishment of nurseries on the lines of those that had been set up in the Soviet Union. These nurseries should develop as an integral part of the child-welfare organization : Its aims would be not only to provide proper education to the mothers and children but also provide support in child care during the mother's working hours. And finally the Bhore Committee recommended a maternity benefit scheme that would help the pregnant and nursing woman to overcome the strain resulting from the overwork that she is invariably subjected to. The committee recommended compulsory abstentiesm from work for working women six weeks prior and six weeks after delivery alongwith a grant of a maternity bencfit.

\section{Financing of the National Health Service}

At the time of the Bhore Committee the amount of expenditure for medical relief and public health by the state was very small. It ranged from (in 1944-45) a low of 2.8 annas (or 16.8 paise) per capita in Central provinces and Berar to a high of 10.9 annas (or 65.4 paise) in the Bombay Province which was $3.1 \%$ and $4.5 \%$, respectively, of total provincial government expenditure.

The Bhore Committee comments that in Great Britain in 1934-35 (prior to NHS) the government was spending as much as $20.4 \%$ of their total expenditure on health care services. Even the United States government spent $13.8 \%$ of its total expenditure in 1938 on health services. "It is hence obvious that governments in India have been spending an unduly small proportion of their incomes on health administration and there is therefore every justification for demanding that the ratio of expenditure under this head must be raised considerably. The government should be prepared to increase the money spent on health to atleast $15 \%$ of the total expenditure."

The development of the plan as envisaged by the Committee would cost the government as little as $1 \mathrm{Re}$ and annas 14 (Rs. 1.87) per year in the first ten years (1945-46 prices) on recurring expenditure and Re. 1 anna 1 and paise 5 (Rs. 1.11) per capita per year on non-recurring expenditure. The former would be spent from state revenues and the latter from loans (the recurring cost includes amortisation payments for non-recurring expenditure). This would have amounted to only $1.33 \%$ of GNP.

From the percentage distribution of the national health schemes expenditure it is clear that a little more than half of the total (both in case of recurring and non-recurring) would go to the three million unit schemes which forms the core of the plan; and over one-half of this would be spent on Primary units that would provide health services at virtually the doorstep of the population.

The other major head of expenditure is professional medical education which has been allocated $11 \%$ of the plan's share. Of this nearly half would be spent on the education and training of doctors and about one-third on nursing education (in the case of non-recurring cost $68 \%$ of professional education expenditure would be for training of doctors).

On the non-recurring side, water supply and drainage have been allocated a major share. By its nature it is largely a capital expcnditure and the recurring costs are mainly charges for maintenance of the system. 
An interesting component of expenditure of the Bhore Committee's plan is provision for housing accommodation for all health staff involved in the three million unit scheme. This expenditure (on the nonrecurring side) is $30 \%$ of total non-recurring expenditure and a whopping $58.52 \%$ of the three million unit non-recurring expenditure.

Two other important items (on the recurring side) are salaries and drugs. In the three million unit scheme salaries constitute $69.39 \%$ of the total expenditure on the three million units and drugs $7.04 \%$. Of course this is only for the 3 million units scheme. Salaries and drugs would also be important components in the other schemes of the Bhore Committee plan. Finally the Bhore Committee strongly recommends that it should be a statutory obligation on governments to spend a minimum of $15 \%$ of their revenues on health activities.

The Bhore Committee ends its report on a clear note of urgency for implementation of the plan in its full form. "The existing state of public health in the country is so unsatisfactory that any attempt to improve the present position must necessarily involve administrative measures of such magnitude as may well seem to be out of all proportion to what has been conceived and accomplished in the past. This seems to us inevitable, especially because health administration has so far received from governments but a fraction of the attention which it deserves in comparison with other branches of governmental activity. We believe that we have only been fulfilling the duty imposed on us by the Government of India in putting forward this health programme, which can in no way be considered as extravagant either in relation to the standards of health administration already reached in many other countries or in relation to the minimum requirements of any scheme which is intended to demonstrate an appreciable improvement in the health of the community. For reasons already set out, we also believe that the execution of the scheme should not be beyond the financial capacity of governments.

\section{Relevance of Bhore Committee Today}

Health services today are as inadequate and underdeveloped as they were during the time of the Bhore Committee. The analysis of the health situation by the Bhore Committee in the early forties would hold good if a similar enquiry is undertaken today, nearly half a century later. The enclave pattern of development of the health sector continues even today-the poor, the villagers, women and other underprivileged sections of society, in other words the majority still do not have access to even basic health care.

Instead of the national health care services that the Bhore Committee had envisaged, which would be available to one and all irrespective of their ability to pay, further, modification of health care services took place strengthening the operation of market forces in this sector.

It is true that mortality has declined, but there is no evidence of decline in morbidity. One suspects that the latter must have increased manifold due to mortality reduction. Infact the little evidence of classwise mortality differentials indicate that mortality decline among the poorer section is only marginal. The aggregate figures are biased by the favourable conditions that the top $20 \%$ of the population has carved for itself. It is this improvement that reflects the aggregate improvement in all spheres of India's development. 
The recommendations of the Bhore Committee were not rejected outright by the governments of Independent India. The principles were accepted in the First Five Year Plan but the contents were very selectively focused. The rest is history.

Forty years later we see that only one target of the Bhore Committec's recommendations was realised i.e., the production of doctors. But the unfortunate aspect of this development is that these doctors have bcen produced not for the 'salaried service' in the national health plan that the Bhore Committee had envisaged but for adding to the ranks of private medical practitioners. What is even more unfortunate is that these private medical practitioners have been produced at the expense of the public exchequer and they profit from the practice of medicine without any significant state regulation of their activity.

The other recommendations of the Bhore Committee have been gradually diluted and unfocussed. For instance the Primary Health Centre which we have at present is not even an apology of what the Bhore Committee had outlined-the 75 bedded Primary Health unit with 6 doctors, 20 nurses, 6 public nurses and a host of other paramedical staff catering to a 10,000 to 20,000 population then proposed, as against a six bedded primary health centrc with one doctor, 1 nurse midwife, 1 public health nurse, 6 auxiliary nurse midwives and 6 Male Multipurpose Workers (MMW) for a 30,000 to 80,000 population now existing. It will only add to the humiliation if we compare the other recommendations to the achievements today.

Another aspect of the health sector, besides production of doctors, which has developed considerably is the production of drug formulations, especially in the private sector. It is logical that this should develop to support the large mass of private medical practitioners. Even the production of pharmacists has increased phenomenally from 1 pharmacist to 4 million population in 1942 43 to 1 pharmacist to 3500 population in 1987.

Universal coverage of the population through some health plan is historically well entrenched today, whether this be through health insurance or state run health services. There is no developed country, whether capitalist or socialist, which has not insured, through either of the above means or a combination, a minimum standard of health care for its population. In socialist countries the state provides health care, among other 'social services', as a basic right of the citizen. In capitalist countries social security has evolved under the concept of a welfare state and health is one of the prominent elements.

India was fortunate in having a National Health Services plan prior to independence but it missed the bus. Inadequate resources may appear to be a strong reason for not implementing the Bhore Committee plan but when resource allocations are studied carefully we clearly see that financial resources were largely committed to areas which helped the development of capitalism. The focus was clearly in that direction leaving for the social services like health, education and housing only residual resources. Over the years more than $80 \%$ of plan resources have been allocated to economic services whose benefits have been appropriated by a small class of capialist farmers and the bourgeoisie. For instance most of the resources expanded on agriculture and irrigation have benefited the rich and middle peasantry and agri-business (fertiliser, pesticide and modern farm 
implements industry). The development of power, basic or infrastructure industry, transport and communication has largely helped industrial capitalism to prosper, with the public sector industry invariably absorbing vast losses.

The same pattern of expenditure is seen in the expending of revenue resources of the state. The 'Economic Services' and nondevelopment expenditure (defence, police and administration) eat away more than $80 \%$ of these resources leaving only a mere lip-service worthiness for the social services sector. We will not extend this explanation further because it is very well documented by various scholars.

Given the subsistence or even below subsistence standard of life in India, the demand for a national health service assumes a great urgency, and hence resource constraint cannot be an issue. In such a socioeconomic setting the state's responsibility in providing a free minimum standard of health care alongwith other 'social services' becomes even more important because the majority of the households do not have a surplus, after spending on their basic necessities such as food, clothing, water and shelter to take care of their basic social needs such as education and health care. Hence the demand for a national health service is justified on just this ground let alone other reasons.

The Bhore Committee provides wide framework to develop a national health service. And we feel that with suitable modifications to accommodate present conditions and considerations a national health service can be evolved within a single plan period.

One of the main arguments against national health service is that public medical institutions that presently exist both are inefficient and inadequately provided, besides being impersonal and corruption ridden. This may be true to some extent but this simple argument can be easily countered by showing that the inefficiency and inadequacy of public hospitals is largely due to the existence of the private health sector. If there was no private health sector then the public services would have no choice but to function properly and people, as well as the state, would ensure this because the alternative private health sector would not be there.

It is well established that state monopolies function quite smoothly and efficiently and many also make huge profits that even large private corporations envy. The public sector petroleum industry (ONGC, India Oil etc.) for instance, make whopping profits. Similarly public services like railways, electricity supply, water supply, telephones; public road transport, banking etc. function quite efficiently and provide people a fairly adequate services where they exist. We are not saying that they don't have problems or they are running at optimal efficiency. All we want to point out is that a public sector monopoly can deliver goods, provided the private sector does not have vested interests attached to it. For example a large number of state infrastructure industry make heavy losses not because they are inefficient but because they provide subsidised inputs to the private industrial sector. We would like to round off this argument by saying that today most of the large and medium private corporations are thriving with resources of public financial institutions like UTI, LIC, public sector banks etc. Thus there should be no constraint on finances for setting up a national health service.

The support for privatisation has gained strength in the last one year with per- 
estroika and glasnost in the socialist countries. In India the health sector too has got caught in this wave and beginnings have been made with the introduction of usercharges in public health institutions. The small mercies that the under privileged had in the form of free public health services too seem to be getting out of their reach. This must be prevented and countered, and the demand for a national health service must become vociferous before the corpo- rate and HMO type of 'health revolution' takes over in India and uproots the small legacy of public health services we already have. We have to demand that health becomes a right which the state must provide for unconditionally from the revenue it collects from citizens. The Bhore Committee report, though nearly half a century old, gives us the basic foundation from which we can build the apparatus of a national health service.

\section{OVERALL PROGRAM STATUS}

Immunization programs in developing countries have made remarkable progress since the inception of the Expanded Program on Immunization (EPI) in 1974 when it was estimated that less than 5\% of the world's infants were adequately immunized. Today, some $70 \%$ are being reached with a protective course of immunization by the first year of life. The development of the capacity to achieve these levels of coverage of infants represents a major public health triumph for the end of the decade of the 1980s.

High immunization coverage levels need to be achieved and sustaincd. Intensified immunization activities, including the use of national or local immunization days, should be directed at areas of low immunization coverage or where there is continuing transmission of disease. Each country should have an Immunization Plan of Action with integrates the targets of achieving at lcast $90 \%$ immunization coverage with all EPI antigens, poliomyelitis eradication, neonatal tetanus elimation and measles reduction, and, in areas. of risk, delivery of appropriate micronutrient supplementation. 